\title{
Respiratory manifestations of Marfan syndrome: a narrative review
}

\author{
Mon Hnin Tun ${ }^{1 \#}$, Bryan Borg ${ }^{2,3 \#}$, Maurice Godfrey ${ }^{4}$, Nancy Hadley-Miller ${ }^{5}$, Edward D. Chan ${ }^{2,3,6}$ \\ ${ }^{1}$ Department of Pediatrics, University of Alberta, Edmonton, Canada; ${ }^{2}$ Division of Pulmonary Sciences and Critical Care Medicine, University of \\ Colorado Anschutz Medical Campus, Aurora, CO, USA; ${ }^{3}$ Rocky Mountain Regional Veterans Affairs Medical Center, Aurora, CO, USA; ${ }^{4}$ Munroe \\ Meyer Institute, University of Nebraska Medical Center, Omaha, NE, USA; ${ }^{5}$ Department of Orthopedics, University of Colorado Anschutz Medical \\ Campus, Children's Hospital Colorado, Aurora, CO, USA; ${ }^{6}$ Department of Academic Affairs, National Jewish Health, Denver, CO, USA \\ Contributions: (I) Conception and design: MH Tun, B Borg, ED Chan; (II) Administrative support: None; (III) Provision of study materials or \\ patients: None; (IV) Collection and assembly of data: All authors; (V) Data analysis and interpretation: All authors; (VI) Manuscript writing: All \\ authors; (VII) Final approval of manuscript: All authors. \\ \#These authors contributed equally to this work. \\ Correspondence to: Edward D. Chan, MD. D509, Neustadt Building, National Jewish Health, 1400 Jackson St., Denver, CO 80206, USA. \\ Email: ChanE@NJHealth.org.
}

Objective: The prevalence of Marfan syndrome (MFS) is estimated to be 1 in 10,000 to 15,000 individuals, but the phenotype of MFS may not be apparent and hence its diagnosis may not be considered by clinicians. Furthermore, the effects of MFS on the lungs and breathing are underrecognized despite the high morbidity that can occur. The objective of this Narrative Review is to delineate the molecular consequences of a defective fibrillin-1 protein and the skeletal and lung abnormalities in MFS that may contribute to respiratory compromise. It is important for clinicians to be cognizant of these MFS-associated respiratory conditions, and a contemporaneous review is needed.

Background: MFS is an autosomal dominant, connective tissue disorder caused by mutations in the FIBRILLIN-1 (FBN1) gene, resulting in abnormal elastic fibers as well as increased tissue availability of transforming growth factor-beta (TGF $\beta$ ), both of which lead to the protean clinical abnormalities. While these clinical characteristics are most often recognized in the cardiovascular, skeletal, and ocular systems, MFS may also cause significant impairment on the lungs and breathing.

Methods: We searched PubMed for the key words of "Marfan syndrome," "pectus excavatum," and "scoliosis" with that of "lung disease," "breathing", or "respiratory disease." The bibliographies of identified articles were further searched for relevant articles not previously identified. Each relevant article was reviewed by one or more of the authors and a narrative review was composed.

Conclusions: Though the classic manifestations of MFS are cardiovascular, skeletal, and ocular, FBN1 gene mutation can induce a variety of effects on the respiratory system, inducing substantial morbidity and potentially increased mortality. These respiratory effects may include chest wall and spinal deformities, emphysema, pneumothorax, sleep apnea, and potentially increased incidence of asthma, bronchiectasis, and interstitial lung disease. Further research into approaches to prevent respiratory complications is needed, but improved recognition of the respiratory complications of MFS is necessary before this research is likely to occur.

Keywords: Marfan syndrome (MFS); lung disease; sleep apnea; kyphoscoliosis; pectus excavatum; emphysema

Submitted Jul 05, 2021. Accepted for publication Sep 03, 2021.

doi: $10.21037 /$ jtd-21-1064

View this article at: https://dx.doi.org/10.21037/jtd-21-1064 


\section{Introduction}

Marfan syndrome (MFS) is a relatively common autosomal dominant, systemic connective tissue disorder found worldwide with no predilection for either sex or ethnicity. After revision of the diagnostic criteria in 2010 (1), the estimated prevalence has fallen from 1 in 5,000 to a more current estimate of 1 in 10,000 to 15,000 individuals $(2,3)$. MFS is caused by mutation of the FIBRILLIN-1 (FBN1) gene located on chromosome 15 (15 q 21.1) and is a disorder associated with multiple organ system manifestations and broad clinical variability that may lead to serious morbidity and early mortality (4). Though the classic manifestations of MFS are cardiovascular, skeletal, and ocular, up to 10 percent of individuals will have MFSassociated respiratory disorders such as chronic obstructive pulmonary disease (COPD)/emphysema, spontaneous pneumothorax (SP), bronchiectasis, and sleep disordered breathing as well as thoracic skeletal abnormalities that may impair respiratory function (3,5-7). A recent MFS casecontrol study with gender and age-matched controls found an increased frequency of death from respiratory causes (OR 3.0; CI: 1.4-6.3, $\mathrm{P}=0.005$ ) (3). Since the diagnosis of MFS may not be considered by clinicians and its respiratory effects may be overlooked or underrecognized, a more contemporaneous review of the literature is needed on the impact of MFS on the respiratory system. The goal of this review is to elaborate how a defective fibrillin-1 protein may contribute to the skeletal defects, lung abnormalities, and sleep disordered breathing in MFS that may lead to respiratory compromise. We will also discuss how losartan, presently used by some to prevent the vascular abnormalities (aortopathy) associated with MFS, may or may not benefit the respiratory complications of MFS despite conflicting evidence for its efficacy in aortopathy.

We present the following article in accordance with the Narrative Review reporting checklist (available at https:// dx.doi.org/10.21037/jtd-21-1064).

\section{Methods}

We searched PubMed for the key words of "Marfan syndrome," "pectus excavatum," and "scoliosis" with that of "lung disease," "breathing", or "respiratory disease." The bibliographies of identified articles were further searched for relevant articles not previously identified. Each article was reviewed by one or more of the authors and a Narrative Review was composed.

\section{Fibrillin-1 structure and function}

The glycoprotein fibrillin-1 forms a long flexible monomer that is the backbone of the extracellular microfibril, i.e., microfibrils are composed of polymers of fibrillin-1 (Figure 1A, top panel). Two major models show how fibrillin-1 aligns in microfibrils, namely the molecular hinge model and the one-third staggered model (8). Mature microfibrils are cross-linked via reducible disulfide bonds and nonreducible $\varepsilon$-( $\gamma$-glutamyl)-lysine cross-links to stabilize the three dimensional structure and to provide additional strength to withstand mechanical forces in tissues (9). The N-terminus of fibrillin-1 is highly interactive, capable of binding the $\mathrm{C}$-terminus of other fibrillin-1 molecules as well as other molecules such as MAGPs-1 and -2, fibulins $-1,-2$, and -5 , versican and heparan sulphate to form microfibrils (10).

Microfibrils are found ubiquitously in connective tissue and serve as the template for elastic fibers $(11,12)$. To form elastic fibers, microfibrils form a meshwork around a central elastin core (Figure 1A, top panel) and are present in many tissues such as the skin (13), arteries (14), ligaments (15), and lungs (16). Elastic fibers play a dominant role in conferring elasticity and resilience in these structures. Hence, microfibrils are essential for integrity of many body tissue structures, including skin, blood vessels, lung parenchyma, cardiac valves, and ocular ligaments (17).

Microfibrils play a role in tissue homeostasis, sequestering and storing the latent forms of transforming growth factor-beta (TGF $\beta$ ), wherein TGF $\beta$ is bound to a latency-associated peptide (LAP), forming the Small Latent Complex (SLC). When the SLC duplex is bound to latent TGF $\beta$ binding protein (LTBP) (18) (Figure 1A, bottom panel), this triplex is known as a Large Latent Complex (LLC). The LLC sequesters and stores TGF $\beta$ in an inactive form (19). The mechanism for this storage is that the C-terminus of LTBP binds to fibrillin-1 present on microfibrils as fibrillin-1 is structurally homologous to LTBP (Figure 1A, bottom panel) $(20,21)$. In the presence of a mutated fibrillin-1 protein, LTBP binding to fibrillin-1 is reduced in the microfibril-whether due to the abnormal fibrillin-1 protein or reduced amount of it-resulting in the inability to keep TGF $\beta$ sequestered in the LLC and leading to increased bioavailability of free TGF $\beta$ (Figure 1B) and overactivation of downstream TGF $\beta$ signaling cascades (18). There are two pathways of TGF $\beta$ intracellular signaling, canonical and non-canonical. In the canonical pathway, Smad proteins mediate the intracellular 
A Normal microfibril, elastic fiber, and LTBP binding

Elastic fiber [short-axis view]

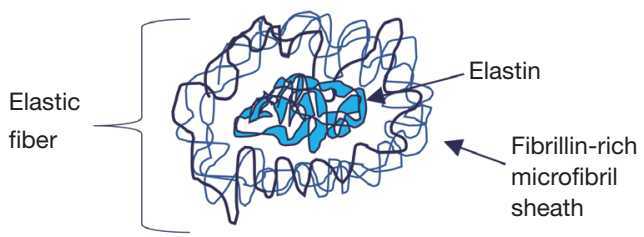

Normal elastic fiber \& associated proteins [long-axis view]

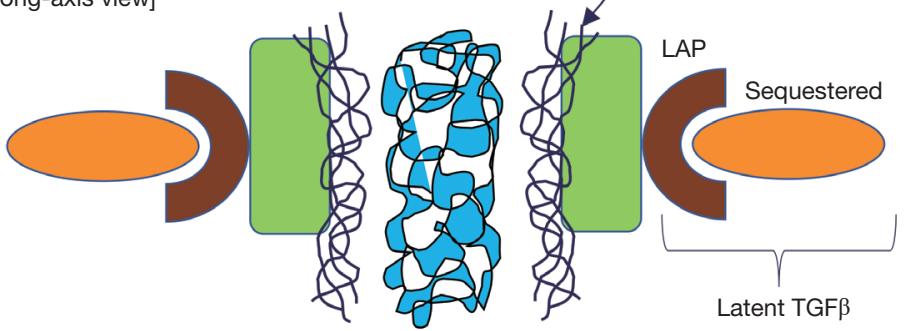

B Abnormal fibrillin-1 \& microfibril in MFS

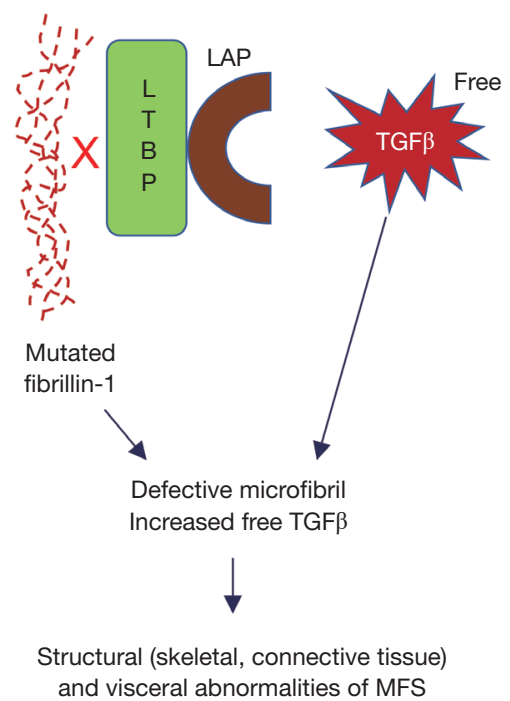

Figure 1 Diagram of normal microfibril, elastic fibers, and associated proteins. (A) Normal state: fibrillin-1 is a key structural component of microfibrils. Microfibrils serve several functions including binding to LTBP, combining with elastin to form elastic fibers (top panel) and keeping TGF $\beta$ sequestered (bottom panel). (B) Marfan syndrome: with abnormal fibrillin-1, LTBP is unable to bind the abnormal fibrillin-1 protein present on the microfibrils and thus unable to keep TGF $\beta$ sequestered. As a result, there is both abnormal elastic fibers and increased free TGF $\beta$ in tissues. LTBP, latent TGF $\beta$-binding protein; LAP, latency-associated peptide; TGF $\beta$, transforming growth factor-beta; MFS, Marfan syndrome.

signaling of TGF $\beta$, and enhanced nuclear translocation of $\mathrm{pSmad} 2$ is an indicator for TGF $\beta$ signaling in both murine models and MFS patients $(22,23)$. In the non-canonical pathway, p38 and extracellular-signal regulated kinase 1/2 (ERK1/2) signaling pathways are the main mediators of intracellular TGF $\beta$ signaling (19). Both canonical and noncanonical pathways eventually regulate production of matrix metalloproteinases (MMP) and there is evidence that both pathways may contribute to pathology in MFS through this mechanism. The combined pathophysiological effects of mutated fibrillin-1 protein and increased free TGF $\beta$ levels in tissues account for the protean clinical manifestations of MFS as outlined in Table 1. However, the revised Ghent criteria placed greater emphasis on aortic root abnormalities and ectopia lentis in the diagnostic criteria of MFS (Table 2) (1).

\section{Respiratory system manifestations of MFS}

\section{Chest wall deformity}

Congenital chest wall deformities that include pectus excavatum and pectus carinatum-occurring singularly or in combination-are present in up to $70 \%$ of MFS subjects (Figure 2A) (26). Current evidence indicates that these deformities, in particular, pectus excavatum with or without vertebral deformities, may restrict chest wall movement and result in restrictive physiology $(27,28)$. Quantifying lung function using current standards in patients with MFS is potentially misleading. The reason is that standing height is used to determine predicted values for pulmonary function tests, but due to abnormal arm and leg length in MFS, this method may lead to underestimation of lung function in this population. One prior study used an extrapolated sitting height, as opposed to standing height, to standardize expected spirometry results to comparison databases due to the appendicular skeletal elongation (particularly in leg length) seen in MFS (28). This study determined that restrictive lung disease due to thoracic cage abnormality in MFS occurs only patients with moderate to severe pectus excavatum or scoliosis. Hypoventilation that ensues with severe chest wall restriction may result in hypoxemia and hypercapnia. While diminished lung function in patients with severe pectus excavatum may improve following surgical correction (27), the need for such surgery is 
Table 1 Clinical features of Marfan syndrome (4,24,25)

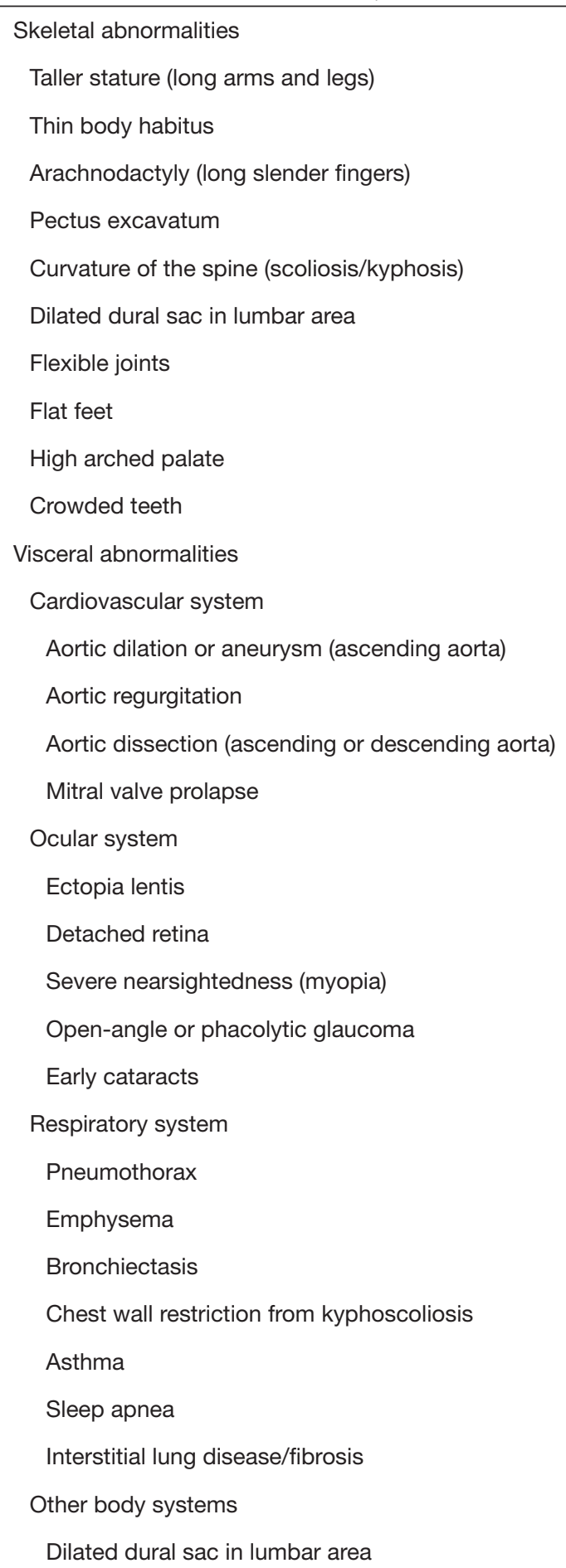

uncommon. If required, surgery should be delayed whenever possible until adolescence to prevent recurrence as a result of normal human growth (29).

\section{Spinal deformity}

Progressive spinal deformities are commonly found in MFS $(30,31)$. Scoliosis is the most common spinal deformity, affecting $>50 \%$ of MFS subjects with the curve apex occurring at multiple sites within the vertebral column. Despite this large percentage of MFS individuals with scoliosis, many of the curves are minor with an estimate of $10 \%$ to $20 \%$ that would require interventional treatment. However, moderate to severe scoliotic curves in MFS individuals may result in marked reductions in lung volume and spirometric measures that are suggestive of restrictive ventilatory defects (28). Like idiopathic scoliosis, most thoracic curve apices are to the right and the lumbar apices are to the left (32). However, unlike idiopathic scoliosis, where the preponderance of severe curvatures is in females, the prevalence of scoliosis is equal among males and females with MFS. Curves can occur at any age in MFS individuals with all scoliotic curves progressing at a faster rate than that of idiopathic scoliosis (31). The therapeutic impact of bracing is believed to be not as effective in MFS as in idiopathic scoliosis but, to date, there have been no comparative trials (33).

In the sagittal plane, the spine profile of individuals with MFS varies significantly. The most predominant sagittal deformity is marked hyperkyphosis (thoracic kyphosis of $>50$ degrees) which occurs in approximately $40 \%$ of MFS individuals (32).

A second issue in the sagittal profile of the spine is at the junction between the thoracic region and the lumbar region, frequently known as the transition zone. In normal individuals, lumbar lordosis is a sagittal curve in the low back which is in the opposite direction of the thoracic region. Normal lordotic angles vary widely with most individuals measuring between 20 and 45 degrees (34). This transitions into thoracic kyphosis, which typically measures between 20 to 40 degrees in those under 50 years of age and often increases with age (35). Of significance is the transition between these two major sagittal curvatures which occurs across one or two vertebrae usually cephalad to the second lumbar vertebrae. Due to the abnormalities of the major sagittal curves of those individuals with MFS, the transition zone can move cephalad or caudad to the second lumbar vertebra, resulting in a straightening of the normal spinal contours. If the transition zone moves cephalad, this manifests with so-called "straight back" sign (Figure $2 B$ ) or even thoracic lordosis (31). The transition vertebra can also deform over time resulting in significant wedging of 
Table 2 Diagnostic criteria for Marfan syndrome based on revised Ghent criteria (1)

\begin{tabular}{|c|c|}
\hline In the absence of family history & In the presence of family history \\
\hline Aortic root dilatation $Z$ score $\geq 2$ or dissection AND FBN1 mutation & $\begin{array}{l}\text { A systemic score } \geq 7 \text { points AND family } \\
\text { history of } \text { MFS }^{\star}\end{array}$ \\
\hline $\begin{array}{l}\text { Aortic root dilatation } Z \text { score } \geq 2 \text { AND systemic score } \geq 7 \text { pts (when ectopia lentis is absent } \\
\text { and the FBN1 status is either unknown or negative), an MFS diagnosis is confirmed by } \\
\text { the presence of sufficient systemic findings ( } \geq 7 \text { points, according to a scoring system) } \\
\text { confirms the diagnosis* }\end{array}$ & $\begin{array}{l}\text { Aortic root dilatation } Z \text { score } \geq 2 \text { above } \\
20 \text { years-old, } \geq 3 \text { below } 20 \text { years-old }+ \text { family } \\
\text { history of } \text { MFS }^{*}\end{array}$ \\
\hline $\begin{array}{l}\text { Ectopia lentis AND a FBN1 mutation associated with aortic root dilatation = MFS. In } \\
\text { the presence of ectopia lentis, but absence of aortic root dilatation/dissection, the } \\
\text { identification of a FBN1 mutation previously associated with aortic disease is required } \\
\text { before making the diagnosis of MFS }\end{array}$ & \\
\hline
\end{tabular}

${ }^{*}$, without discriminating features of Shprintzen-Goldberg syndrome, Loeys-Dietz syndrome, or vascular Ehlers Danlos syndrome - AND after TGFBR1/2, SMAD3, TGFB2, TGFB3, collagen biochemistry, COL3A1 testing if indicated.

the vertebral body (31). This phenomenon contributes to overall biomechanical instability of the spine and back pain. An abnormally straight back where there is a loss of the normal upper thoracic spinal kyphosis, can lead to a reduced antero-posterior diameter of the thoracic cage.

Kyphoscoliosis is the predominant spinal deformity of MFS in which scoliosis occurs in conjunction with a sagittal hyperkyphotic deformity as defined above (Figure 2C). This type of kyphoscoliosis is associated with impairment of lung function and breathing when the scoliosis is severe, as measured by a Cobb angle $>70$ degrees. However, decline in the forced vital capacity can be seen at scoliotic angles as low as 55 degrees (36). Additionally, when the peak or apex of the deformity is more cephalad or higher in the spinal column, the more deleterious effect it may have on lung function (37). One longitudinal study found that severity of hyperkyphosis was more likely to be associated with a decline in pulmonary function in women but not in men (38).

When severe pulmonary restriction from both vertebral and chest wall deformities develops in MFS individuals less than ten years of age, regardless of underlying etiology, the resulting condition is called Thoracic Insufficiency Syndrome (TIS). Aggressive conservative and/or surgical intervention may be required for these children to aid in the continued growth of the thoracic cage and to prevent or ameliorate further deterioration in respiratory function $(39,40)$.

\section{COPD/emphysema}

The emphysema form of COPD is defined by abnormal enlargement of distal airspaces due to destruction of the alveolar walls. MFS patients may develop emphysema even if they never smoked. This finding is corroborated in mice wherein disruption of either the entire $F b n 1$ gene or a targeted 6 kilobase deletion is linked to developmental emphysema $(41,42)$.

Abnormalities in microfibril and elastic fibers due to mutated fibrillin-1 protein predispose to loss of elasticity in the lungs, leading to small airway and bronchiolar flaccidity, premature airway closure, and air trapping, resulting in obstructive physiology and hyperinflation $(43,44)$. In one Italian case series of all patients referred to a centerof-excellence for MFS, $44 \%$ of MFS subjects had an obstructive spirometry pattern, diffusion impairment, and/ or hyperinflation which are all suggestive of emphysema. Only $37 \%$ had normal spirometry, and despite $45 \%$ of the patients having moderate to severe rib cage abnormalities, only $19 \%$ had restrictive spirometric measures (45). In comparison, the contemporaneous prevalence of obstructive lung disease in Italy was around 11\% for COPD and around $6 \%$ for asthma $(46,47)$. In a recent study of MFS patients who either underwent major corrective surgery for thoracic cage or vascular deformities or were deemed not to require surgery, pulmonary function testing using arm span as a surrogate for height revealed a tendency toward obstructive defect with air trapping in both populations rather than a restrictive defect (48). This unexpected pulmonary pathophysiologic finding was more prominent in those who had required surgery.

Immunohistochemical analyses of human lung tissues 
A Pectus excavatum in a Marfan subject

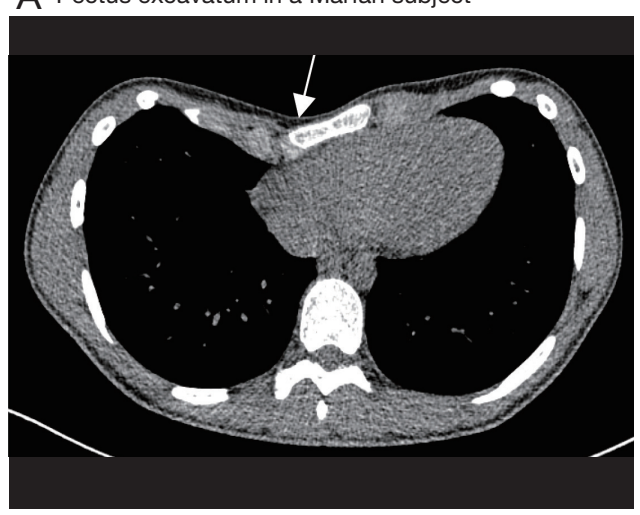

C Kyphoscoliosis in a Marfan individual
B Straight back in a Marfan individual

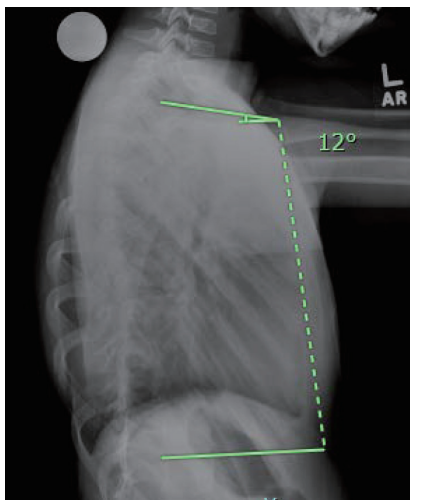

$\frac{L}{A R}$

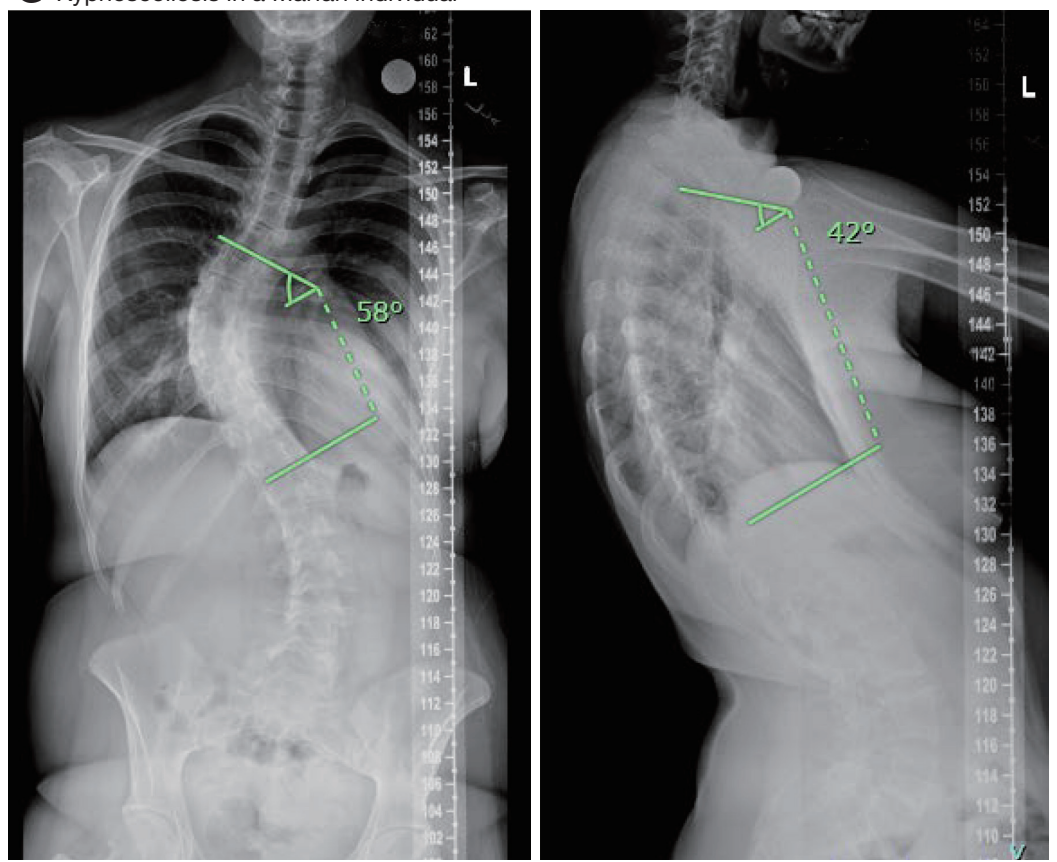

Figure 2 Chest CT and spinal radiograph of patients with MFS. (A) Axial chest CT scan of a MFS individual with pectus excavatum (arrow). (B) Lateral chest radiograph of a MFS subject with a "straight back" sign. A modified Cobb angle is 12 degrees with the normal range of thoracic kyphosis being 20 to 40 degrees. (C) Anterior-posterior spinal radiograph of a 15 -year-old girl with MFS exhibiting severe scoliosis with a Cobb angle measurement of 58 degrees (left panel). Lateral spinal radiograph showing a moderate kyphosis of 42 degrees (normal range 20 to 40 degrees) (right panel). MFS, Marfan syndrome.

with abnormal fibrillin-1 demonstrate abnormal or degraded elastic fibers, loss of alveolar wall integrity, and emphysema-related morphological abnormalities $(49,50)$. In an MFS case series of two lung biopsies and three autopsies, distal acinar emphysema were found in all patients (51). On imaging, distal acinar emphysema appears subpleural and is radiographically termed paraseptal emphysema. This is in contrast with centrilobular emphysema (most common form seen in smokers) and panlobular type (more commonly seen in alpha-1-antitrypsin deficiency). Though paraseptal emphysema is the most common type seen in MFS, centrilobular and panlobular emphysema have also been rarely reported. Over time and with continued hyperinflation injury, paraseptal emphysema may coalesce into large cystic lesions, or blebs, and even contribute to large bullae or giant bullous emphysema (52). These lesions are prone to rupture, placing MFS individuals with paraseptal emphysema at increased risk for secondary 
pneumothoraces-discussed below. Current medical management of MFS patients with emphysema is similar to that seen in individuals without MFS.

Overexpression of TGF $\beta$ may also play a role in emphysema development. TGF $\beta$ was found to be elevated in lung tissues of smokers with COPD (53), of mice with FBN1 gene mutation (54), and in mouse lungs following exposure to cigarette smoke (55). Much of the evidence supporting this pathway lies in research surrounding aortic pathology in MFS. In the normally highly elastic thoracic aorta, it is known that fibrillin-1-containing microfibrils bind LTBP and this limits the bioavailability and local activity of TGF $\beta$. In MFS, increased TGF $\beta$ signaling as well as abnormal elastic fibers play a central role in aortic aneurysm formation, the precursor lesion to aortic dissection or rupture, the most feared and deadly complications in MFS (56,57). Perhaps such pathophysiologic process in the aortic wall may also be occurring in the lungs, resulting in emphysema and bronchiectasis.

\section{Pneumothorax}

The "lifetime" incidence of SP in individuals with MFS is estimated to be $4 \%$ to $14 \%$ in three American cohorts, with more recent estimates trending to the lower end of that range of $\sim 4 \%(=4,000$ per 100,000$)(5,58,59)$. For comparison, the annual incidence of pneumothorax in the general population of the United States is 7.4 per 100,000 in men but only 1.2 per 100,000 in women (60). Despite these limited data and being conservative, SP appears significantly more common in MFS than the general population. Pneumothorax as the presenting finding in the initial diagnosis of MFS is uncommon, especially in adults, but occurs frequently enough to be included in the 2010 revised Ghent criteria for diagnosis of MFS (1). In general, patients with SP tend to be taller than the average individual of the same age group and males are about 6 to 10 times more likely to have blebs both in the general population and in MFS $(58,61)$. In MFS patients with pneumothoraces, bullous lung disease and paraseptal emphysema are often seen on CT imaging, particularly in the apical regions. The predilection for defects in the lung apices may be related to defective elastic fibers in combination with mechanical effects of gravity increasing local stresses in the region (5). In one study, all MFS patients with history of SP were also found to have obstructive ventilatory defect and diffusion impairment which could be consistent with underlying emphysema (45). Because they are due to underlying structural lung disease, pneumothoraces in patients with MFS are considered secondary SP, in contrast to a primary SP where no known lung disease or deformity is present.

The initial management of a pneumothorax in a patient with MFS is similar to any pneumothorax, including tube thoracostomy drainage or conservative monitoring until resolution. However, because the risk of recurrent pneumothorax in secondary SP may be greater than $50 \%$ particularly with persistent air leak that may prolong resolution time and lengthen hospital stay, measures to prevent recurrence are often recommended during the index hospitalization, especially if an air leak is persistent for $>48$ hours (62). Indeed, in a case series of patients with MFS, 25\% with evidence of pneumothorax had already experienced a recurrence of a second or third SP (5). In other words, in individuals with secondary SP with imaging evidence of blebs and/or bullous disease as the likely precipitant, definitive surgical treatment with pleurodesis, wedge resection, and/or bullectomy performed by videoassisted thoracoscopic surgery is recommended soon after the event $(63,64)$. This approach can lead to reduced recurrent rates of $4 \%$ to $7 \%$, whereas rates after chemical pleurodesis through a thoracostomy tube are higher. Additional preventive measures of pneumothorax in MFS also include avoidance of SCUBA diving, contact sports, and any high intensity exercise that may induce the Valsalva maneuver such as weight-lifting or isometric exercises. To the best of our knowledge, no evidence is yet published in animal models or humans regarding the use or efficacy of preventative medications including losartan (discussed below) to prevent or reduce recurrence of SP in MFS. However, if losartan does indeed have a role in reducing development of paraseptal emphysema, there is a possibility of benefit for preventing SP as well.

\section{Asthma and reactive airways disease}

Asthma, wheezing, and reactive airways disease have been reported in MFS, although the prevalence is unclear. Lung function tests in asthma may be normal at baseline but airway hyperreactivity may be induced in the presence of asthma exacerbators or with methacholine challenge in the pulmonary function laboratory. A small cohort study comparing 22 pediatric patients reported no significant difference in baseline full lung function tests between control and MFS patients, after using extrapolated sitting height in the latter group (65). However, in the 10 children with MFS challenged with methacholine, $37.5 \%$ had evidence 
of "large airways obstruction", and 7 of 10 had "small airways obstruction." With bronchodilator administration, $40 \%$ of those with large airflow limitation had significant response whereas $90-100 \%$ of those with small airways obstruction achieved significant reversal (65). In contrast, methacholine challenge testing is positive in only around $7 \%$ of individuals in the general population (66). The finding of hyper-reactive airways in youth with this method may predict eventual clinical development of asthma. The approximately $30 \%$ higher prevalence of hyper-reactivity found in this study is suggestive of a relationship between MFS and risk of asthma (65). This study was limited by not subjecting the control patients to methacholine challenge.

Asthma risk and allergen sensitivity are better documented in another connective tissue disorder-LoeysDietz syndrome (LDS) — with several clinical characteristics in common with MFS. In LDS, there is heterozygous pathogenic variant in one of six genes encoding receptors or ligands in the TGF $\beta$ pathway-in descending order of frequency: TGFBR2, TGFBR1, SMAD3, TGFB2, SMAD2, and TGFB3. Phenotypic abnormalities common to these two disorders include abnormal aortic elasticity with high risk for aortic dissection or rupture as well as chest wall and spinal deformities. Patients with LDS have strong predisposition for allergic and inflammatory diseases, including atopic dermatitis and asthma. Some LDS patients have been found to have elevated eosinophil counts, immunoglobulin $\mathrm{E}$ levels, and $\mathrm{T}_{\mathrm{H}} 2$ pathway cytokines which are strongly associated with asthma development and severity (67-69). Sharing a downstream pathway could explain an increased risk for asthma or wheezing in the MFS population. Additionally, in both of these connective tissue disorders, it is likely that the mutations not only affect lung parenchyma development, but airway development and stability, leading to predisposition to narrowing and resultant increased risk for obstructive ventilatory defects (67).

Although nebulized or inhaled short and long acting $\beta$-adrenergic agonists like albuterol or formoterol are typically prescribed for asthma, their use is cautioned in patients with MFS due to their potential antagonism of $\beta$-adrenergic-receptor blocker medications, considered by many providers to be an essential therapy for preventing life-threatening aortic and cardiovascular complications of MFS. Instead, antimuscarinics and inhaled glucocorticoids are recommended (70).

\section{Bronchiectasis}

The association of bronchiectasis with MFS is uncommonly described. It was postulated that bronchiectasis in patients with MFS develops due to intrinsic bronchial wall defect from fibrillin-1 degeneration (71) or due to the higher risk of recurrent lung infections if chest wall deformities are present. Recurrent infections and inflammation are part of the "vicious cycle" paradigm thought to predispose to bronchiectasis development (72). There are several case reports on bronchiectasis in MFS patients, both in children $(71,73)$ and adults (74-76). Autopsy of a man with MFS who died from chronic respiratory failure revealed multiple bullae with bronchiectasis of the right middle lobe and both lower lobes (76). In a survey report of 100 adult MFS patients, it was observed that there were two cases of bronchiectasis, two with recurrent respiratory infections and three with tuberculosis (59).

Bronchiectasis is a well-established risk factor for nontuberculous mycobacteria (NTM) lung disease. NTM are opportunists, requiring defects in lung structure or in local/systemic host immunity in order to cause disease in humans. Hence, "idiopathic" bronchiectasis and underlying conditions known to cause bronchiectasis such as cystic fibrosis, primary ciliary dyskinesia, alpha-1-antitrypsin deficiency, or sequela of prior suboptimally-treated infections such as tuberculosis are risk factors for NTM lung disease $(77,78)$. However, NTM lung involvement has also been identified in patients without known risk factors over the last two decades (79), and may be more common in tall and lean individuals with a greater than expected prevalence of scoliosis, pectus excavatum, and mitral valve prolapse, features that are also seen with MFS and other connective tissue disorders $(80,81)$. A recent Korean study evaluated the prevalence of bronchiectasis in 79 adult patients with MFS, attempting to better define the prevalence of NTM in this population by using thoracic CT (82). Bronchiectasis was seen in $28 \%$ of the patients, $13 \%$ had smaller airways dilation (bronchiolectasis), and only 3 patients (4\%) had inflammation of the smallest airways (bronchiolitis). During a median follow-up of 65 months, in which no specifics were given on sputum testing frequency or other evaluation metrics, one patient was diagnosed with pulmonary tuberculosis and another was found to have NTM-positive culture, felt to be low-burden of disease that was not clinically significant (82). 
Over the past decade, likely due to increasing use of high-resolution CT scans, a $30 \%$ to $60 \%$ prevalence of bronchiectasis has been reported in patients with moderateto-severe emphysema in the general population $(83,84)$. However, there are no reports on the prevalence of bronchiectasis coexisting with emphysema in MFS patients; although plausible, it remains unclear to what degree the emphysema and airways dysfunction that can develop in MFS contributes to bronchiectasis formation.

\section{Interstitial lung disease}

Lipton et al. (85) reported a case of bilateral honeycomb lung disease in a patient with MFS complicated by pneumothorax. In 1984, Wood et al. (59) reported four cases of upper lobe lung fibrosis among 100 patients with MFS and postulated that the fibrosis could be the result from the healing process of the damage caused by the stresses in the apical parts of the lung. Beyond these two publications, it is not known whether MFS patients are at risk for lung fibrosis or interstitial lung disease.

\section{Sleep apnea}

The prevalence of sleep apnea in patients with MFS is much higher than in age- and sex-matched controls, with a range of $32 \%$ to $64 \%$ of patients being affected $(86,87)$. A case-control polysomnographic study of 61 patients who fulfilled the revised Ghent criteria for MFS and 26 matched controls revealed that both mild and moderate obstructive sleep apnea were more common in patients with MFS than controls, with $32.8 \%$ vs. $11.5 \%$ having mild disease and $18 \%$ vs. $0 \%$ having moderate disease, respectively (86). Other contemporaneous data reinforce a lower prevalence in the general population, with rates of mild or moderate sleep apnea from $9 \%$ to $24 \%$ and $4 \%$ to $9 \%$, respectively, in American adults depending on gender and age $(88,89)$. The increased frequency of obstructive sleep apnea in MFS is perhaps due to decreased connective tissue elasticity causing collapse of the soft palate and posterior oropharyngeal structures, plus the presence of retrognathia (under-bite) and flattened cheek bones seen with MFS. Central sleep apnea is also seen in patients with MFS, and may be related to their underlying cardiovascular disease (90).

Effects of sleep apnea in patients with MFS are similar to those without the disorder, including increased prevalence of stroke, hypertension, and abnormal heart rhythms such as atrial fibrillation. Aortic root diameter was found to be positively correlated with obstructive sleep apnea diagnosis in a case-control cohort, making detection of sleep disordered breathing of increased importance in patients with MFS (86). Additionally, the severity of sleep apnea may correlate with risk for aortic root dilation, although this has not been consistently found (91). Due to the impact of sleep apnea on quality of life and cardiovascular risk, there should be a low threshold to screen for occult sleep apnea, especially in the presence of chronic fatigue or daytime somnolence. Use of a validated questionnaire or scoring system to aid in risk stratification to help determine need for testing is recommended, including the GOAL, NoSAS or STOP-Bang tools.

\section{Preventative therapy of vascular complications of MFS and implications for MFS-associated lung disease}

Losartan, an angiotensin II type-1 receptor (AT1R) blocker, has been implicated to prevent the aortic root dilatation of MFS in murine models and humans $(54,92)$. In a mutant Fbn1 mouse model, empiric use of this therapy from birth resulted in development of aortic wall and root architecture that were indistinguishable from that of wild-type mice (54). In a cohort of 28 pediatric patients, losartan either alone or in combination with $\beta$-receptor blocker slowed the rate of aortic root dilation compared to $\beta$-blocker therapy alone (93). In two subsequent randomized controlled trials, losartan alone or as add-on therapy was shown to be safe and significantly reduced the aortic root dilatation rate in children and adults compared to $\beta$-receptor blocker alone $(93,94)$. This effect may be due to antagonism of pathogenic TGF $\beta$ signaling $(95,96)$ or cytoplasmic localization of pSmad2 (54) and pSmad3 (97). An alternate pathway for losartan benefit which is independent of its ability to block the AT1R has been posited, including endothelial nitric oxide synthase activation and restoration of normal nitric oxide levels, both of which are considered to be protective of endothelial function (98). However, the efficacy and mechanism of action of losartan in preventing or slowing aortic root widening and decreasing all-cause mortality has become controversial in more recent trials $(95,96,99)$. A 2019 review of losartan with or without $\beta$-blocker therapy regarding aneurysm growth suggested that further clinical trials that assess other adverse aortic outcomes such as dissection, need for surgery, and death are needed before it can be determined if losartan stabilizes or attenuates the aortopathy in MFS (100). Subsequent to this publication, 
a long-term clinical outcome study to the COMPARE trial-with median follow-up period of 8 years and captured $94 \%$ of the original cohort-showed that continued use of losartan (originally added to regular treatment wherein $71 \%$ were on a $\beta$-blocker) was significantly associated with reduced the incidence of aortic dissection and death compared to those in whom losartan was not added (99).

The efficacy of losartan in MFS patients may also be related to the type of FBN1 mutation based on experimental findings in mice. Positive drug effects are seen in mice with mutations that cause haploinsufficiency rather than those that are dominant-negative or heterozygous for wild-type $F b n 1$, possibly due to the wild-type gene overwhelming the deleterious potential of the aberrant gene (101). The murine models $\mathrm{Fbn} 1^{\mathrm{C} 1039 \mathrm{G} / \mathrm{+}}$ and $\mathrm{Fbn} 1^{\mathrm{mgR} / \mathrm{mgR}}$ clinically mimic the most common human FBN1 mutations, both in protean organ system manifestations and in effects on canonical and non-canonical TGF $\beta$ signaling (101-103). Aortic aneurysms are associated with increased signaling of the AT1R, leading to independent activation of the ERK1/2 components of the non-canonical TGF $\beta$ signaling pathway. In $\mathrm{Fbn} 1^{\mathrm{C} 1039 \mathrm{G} /+}$ mice, losartan inhibited ERK1/2 signals and reduced aortopathy (102).

It remains unknown if the skeletal manifestations of MFS improve on losartan therapy, or whether some of the defects may develop as severely or rapidly (101), i.e., some of the mechanical problems related to scoliosis and pectus excavatum and the concomitant respiratory issues may still be problematic despite losartan use (104). Thus, it may be of great value to undertake a prospective studyperhaps analyzed in parallel with current studies examining the effects of treatment on vascular pathology — using both subjective and objective measures on the long-term effects of losartan on the skeletal manifestations of MFS.

Similarly, the translation of the aforementioned pathogenic signaling mechanisms in the context of vascular disease, TGF $\beta$, and losartan to what occurs in human lungs in MFS remains to be determined. However, based on the pathophysiologic mechanisms of MFS-associated emphysema, losartan may prevent the progression of this lung disease, albeit this is highly speculative. The mechanisms for this potential benefit are to date largely elucidated through rodent models in the context of TGF $\beta$, i.e., TGF $\beta$ is induced and excessive in the lungs of mice with cigarette smoke exposure and in the lungs of humans with emphysema (55). Since losartan antagonizes TGF $\beta$ signaling through decreased TGF $\beta$ expression and activation (105), it has the potential to mitigate emphysema in which TGF $\beta$ plays an important pathogenic role. In a murine model with cigarette smoke exposure, systemic administration of a TGF $\beta$-specific neutralizing antibody decreased signaling and alveolar cell death, leading to improved lung architecture and mechanics (55). Use of losartan in the same mice reduced oxidative stress, inflammation, metalloprotease activation, and elastin remodeling, all known insults in emphysema development which are shared with the assumed pathology in MFS $(19,55,101)$. In Fbn 1 mutant murine models, blocking the action of TGF $\beta$ with either neutralizing antibodies or losartan reversed and improved the airway narrowing and abnormal parenchymal architecture and lung function $(54,106)$. A $F b n 1^{\mathrm{mgR} / \mathrm{mgR}}$ murine model showed accelerated deterioration of elastin rich lung tissue, becoming over $85 \%$ less elastic than wild-type mice at 3.5 months of age. AT1R antagonism with losartan attenuated lung tissue degradation resulting in mechanical and structural characteristics which were not different to age-matched wild-type controls determined (106). To recap, since overexpression of TGF $\beta$ may also play a role in smoking-related emphysema in humans (53), of mice with Fbn1 gene mutation (54), and in mouse lungs following exposure to cigarette smoke (55), losartan may potentially mitigate the development of emphysema in humans although this remains speculative. Despite this mechanistic plausibility, losartan has not been tested in humans with the intent to prevent emphysema development.

\section{Conclusions}

Though the classic manifestations of MFS are cardiovascular, skeletal, and ocular, FBN1 gene mutation in the disease can induce a variety of effects on the respiratory system-including thoracic cage abnormalities that mechanically compromise respiratory function, airways disease (emphysema, asthma, and bronchiectasis), and sleep apnea-inducing substantial morbidity in individuals with MFS and being associated with increased mortality. Further research into approaches to prevent respiratory complications is needed, but based on known mechanisms, AT1R blockade holds promise but is unproven for prevention of paraseptal emphysema and secondary pneumothorax complications.

\section{Acknowledgments}

Funding: None. 


\section{Footnote}

Reporting Checklist: The authors have completed the Narrative Review reporting checklist. Available at https:// dx.doi.org/10.21037/jtd-21-1064

Peer Review File: Available at https://dx.doi.org/10.21037/ jtd-21-1064

Conflicts of Interest: All authors have completed the ICMJE uniform disclosure form (available at https://dx.doi. org/10.21037/jtd-21-1064). EDC serves as an unpaid editorial board member of Fournal of Thoracic Disease from Dec 2018 to Jan 2021; Feb 2021 to Jan 2023. The other authors have no conflicts of interest to declare.

Ethical Statement: The authors are accountable for all aspects of the work in ensuring that questions related to the accuracy or integrity of any part of the work are appropriately investigated and resolved.

Open Access Statement: This is an Open Access article distributed in accordance with the Creative Commons Attribution-NonCommercial-NoDerivs 4.0 International License (CC BY-NC-ND 4.0), which permits the noncommercial replication and distribution of the article with the strict proviso that no changes or edits are made and the original work is properly cited (including links to both the formal publication through the relevant DOI and the license). See: https://creativecommons.org/licenses/by-nc-nd/4.0/.

\section{References}

1. Loeys BL, Dietz HC, Braverman AC, et al. The revised Ghent nosology for the Marfan syndrome. J Med Genet 2010;47:476-85.

2. Chiu HH, Wu MH, Chen HC, et al. Epidemiological profile of Marfan syndrome in a general population: a national database study. Mayo Clin Proc 2014;89:34-42.

3. Groth KA, Stochholm K, Hove H, et al. Causes of Mortality in the Marfan Syndrome(from a Nationwide Register Study). Am J Cardiol 2018;122:1231-5.

4. Judge DP, Dietz HC. Marfan's syndrome. Lancet 2005;366:1965-76.

5. Karpman C, Aughenbaugh GL, Ryu JH. Pneumothorax and bullae in Marfan syndrome. Respiration 2011;82:219-24.

6. Pyeritz RE. The Marfan syndrome. Annu Rev Med 2000;51:481-510.
7. Pyeritz RE. Marfan syndrome: improved clinical history results in expanded natural history. Genet Med 2019;21:1683-90.

8. Kielty CM, Sherratt MJ, Marson A, et al. Fibrillin microfibrils. Adv Protein Chem 2005;70:405-36.

9. Gibson MA, Kumaratilake JS, Cleary EG. The protein components of the 12-nanometer microfibrils of elastic and nonelastic tissues. J Biol Chem 1989;264:4590-8.

10. Reinhardt DP, Chalberg SC, Sakai LY. The structure and function of fibrillin. Ciba Found Symp 1995;192:128-43; discussion 143-7.

11. Charbonneau NL, Ono RN, Corson GM, et al. Fine tuning of growth factor signals depends on fibrillin microfibril networks. Birth Defects Res C Embryo Today 2004;72:37-50.

12. Sakai LY, Keene DR, Engvall E. Fibrillin, a new 350-kD glycoprotein, is a component of extracellular microfibrils. J Cell Biol 1986;103:2499-509.

13. Watson RE, Griffiths CE, Craven NM, et al. Fibrillin-rich microfibrils are reduced in photoaged skin. Distribution at the dermal-epidermal junction. J Invest Dermatol 1999;112:782-7.

14. Wagenseil JE, Mecham RP. Vascular extracellular matrix and arterial mechanics. Physiol Rev 2009;89:957-89.

15. Kielty CM, Cummings $C$, Whittaker SP, et al. Isolation and ultrastructural analysis of microfibrillar structures from foetal bovine elastic tissues. Relative abundance and supramolecular architecture of type VI collagen assemblies and fibrillin. J Cell Sci 1991;99:797-807.

16. WRIGHT RR. Elastic tissue of normal and emphysematous lungs. A tridimensional histologic study. Am J Pathol 1961;39:355-67.

17. Thomson J, Singh M, Eckersley A, et al. Fibrillin microfibrils and elastic fibre proteins: Functional interactions and extracellular regulation of growth factors. Semin Cell Dev Biol 2019;89:109-17.

18. Neptune ER, Frischmeyer PA, Arking DE, et al. Dysregulation of TGF-beta activation contributes to pathogenesis in Marfan syndrome. Nat Genet 2003;33:407-11.

19. Benke K, Ágg B, Szilveszter B, et al. The role of transforming growth factor-beta in Marfan syndrome. Cardiol J 2013;20:227-34.

20. Isogai Z, Ono RN, Ushiro S, et al. Latent transforming growth factor beta-binding protein 1 interacts with fibrillin and is a microfibril-associated protein. J Biol Chem 2003;278:2750-7.

21. Dallas SL, Keene DR, Bruder SP, et al. Role of the latent 
transforming growth factor beta binding protein 1 in fibrillin-containing microfibrils in bone cells in vitro and in vivo. J Bone Miner Res 2000;15:68-81.

22. Heldin CH, Miyazono K, ten Dijke P. TGF-beta signalling from cell membrane to nucleus through SMAD proteins. Nature 1997;390:465-71.

23. Loeys BL, Chen J, Neptune ER, et al. A syndrome of altered cardiovascular, craniofacial, neurocognitive and skeletal development caused by mutations in TGFBR1 or TGFBR2. Nat Genet 2005;37:275-81.

24. Al Kaissi A, Zwettler E, Ganger R, et al. Musculo-skeletal abnormalities in patients with Marfan syndrome. Clin Med Insights Arthritis Musculoskelet Disord 2013;6:1-9.

25. Murdoch JL, Walker BA, Halpern BL, et al. Life expectancy and causes of death in the Marfan syndrome. N Engl J Med 1972;286:804-8.

26. Fraser S, Child A, Hunt I. Pectus updates and special considerations in Marfan syndrome. Pediatr Rep 2017;9:7277.

27. Kelly RE Jr, Obermeyer RJ, Nuss D. Diminished pulmonary function in pectus excavatum: from denying the problem to finding the mechanism. Ann Cardiothorac Surg 2016;5:466-75.

28. Streeten EA, Murphy EA, Pyeritz RE. Pulmonary function in the Marfan syndrome. Chest 1987;91:408-12.

29. Nuss D, Obermeyer RJ, Kelly RE Jr. Pectus excavatum from a pediatric surgeon's perspective. Ann Cardiothorac Surg 2016;5:493-500.

30. De Maio F, Fichera A, De Luna V, et al. Orthopaedic Aspects of Marfan Syndrome: The Experience of a Referral Center for Diagnosis of Rare Diseases. Adv Orthop 2016;2016:8275391.

31. Sponseller PD, Hobbs W, Riley LH 3rd, et al. The thoracolumbar spine in Marfan syndrome. J Bone Joint Surg Am 1995;77:867-76.

32. Demetracopoulos CA, Sponseller PD. Spinal deformities in Marfan syndrome. Orthop Clin North Am 2007;38:563-72, vii.

33. Sponseller PD, Bhimani M, Solacoff D, et al. Results of brace treatment of scoliosis in Marfan syndrome. Spine (Phila Pa 1976) 2000;25:2350-4.

34. Been E, Kalichman L. Lumbar lordosis. Spine J 2014;14:87-97.

35. Fon GT, Pitt MJ, Thies AC Jr. Thoracic kyphosis: range in normal subjects. AJR Am J Roentgenol 1980;134:979-83.

36. Harrison RA, Siminoski K, Vethanayagam D, et al. Osteoporosis-related kyphosis and impairments in pulmonary function: a systematic review. J Bone Miner
Res 2007;22:447-57.

37. McMaster MJ, Glasby MA, Singh H, et al. Lung function in congenital kyphosis and kyphoscoliosis. J Spinal Disord Tech 2007;20:203-8.

38. Lorbergs AL, O'Connor GT, Zhou Y, et al. Severity of Kyphosis and Decline in Lung Function: The Framingham Study. J Gerontol A Biol Sci Med Sci 2017;72:689-94.

39. Pehrsson K, Bake B, Larsson S, et al. Lung function in adult idiopathic scoliosis: a 20 year follow up. Thorax 1991;46:474-8.

40. Weinstein SL, Zavala DC, Ponseti IV. Idiopathic scoliosis: long-term follow-up and prognosis in untreated patients. J Bone Joint Surg Am 1981;63:702-12.

41. Gayraud B, Keene DR, Sakai LY, et al. New insights into the assembly of extracellular microfibrils from the analysis of the fibrillin 1 mutation in the tight skin mouse. J Cell Biol 2000;150:667-80.

42. Pereira L, Andrikopoulos K, Tian J, et al. Targetting of the gene encoding fibrillin-1 recapitulates the vascular aspect of Marfan syndrome. Nat Genet 1997;17:218-22.

43. Maslen CL, Glanville RW. The molecular basis of Marfan syndrome. DNA Cell Biol 1993;12:561-72.

44. Turner JA, Stanley NN. Fragile lung in the Marfan syndrome. Thorax 1976;31:771-5.

45. Corsico AG, Grosso A, Tripon B, et al. Pulmonary involvement in patients with Marfan Syndrome. Panminerva Med 2014;56:177-82.

46. Guerriero M, Caminati M, Viegi G, et al. COPD prevalence in a north-eastern Italian general population. Respir Med 2015;109:1040-7.

47. Cazzola M, Puxeddu E, Bettoncelli G, et al. The prevalence of asthma and COPD in Italy: a practice-based study. Respir Med 2011;105:386-91.

48. Kolonics-Farkas AM, Agg B, Benke K, et al. Lung Function Changes are More Common in Marfan Patients Who Need Major Thoracic Surgery. Lung 2019;197:465-72.

49. Koenders MM, Wismans RG, Starcher B, et al. Fibrillin-1 staining anomalies are associated with increased staining for TGF-beta and elastic fibre degradation; new clues to the pathogenesis of emphysema. J Pathol 2009;218:446-57.

50. Robbesom AA, Koenders MM, Smits NC, et al. Aberrant fibrillin-1 expression in early emphysematous human lung: a proposed predisposition for emphysema. Mod Pathol 2008;21:297-307.

51. Dyhdalo K, Farver C. Pulmonary histologic changes in Marfan syndrome: a case series and literature review. Am J Clin Pathol 2011;136:857-63.

52. Shannon VR, Nanda AS, Faiz SA. Marfan Syndrome 
Presenting as Giant Bullous Emphysema. Am J Respir Crit Care Med 2017;195:827-8.

53. Mak JC, Chan-Yeung MM, Ho SP, et al. Elevated plasma TGF-beta1 levels in patients with chronic obstructive pulmonary disease. Respir Med 2009;103:1083-9.

54. Habashi JP, Judge DP, Holm TM, et al. Losartan, an AT1 antagonist, prevents aortic aneurysm in a mouse model of Marfan syndrome. Science 2006;312:117-21.

55. Podowski M, Calvi C, Metzger S, et al. Angiotensin receptor blockade attenuates cigarette smoke-induced lung injury and rescues lung architecture in mice. J Clin Invest 2012;122:229-40.

56. Matt P, Schoenhoff F, Habashi J, et al. Circulating transforming growth factor-beta in Marfan syndrome. Circulation 2009;120:526-32.

57. Takeda N, Hara H, Fujiwara T, et al. TGF- $\beta$ SignalingRelated Genes and Thoracic Aortic Aneurysms and Dissections. Int J Mol Sci 2018;19:2125.

58. Hall JR, Pyeritz RE, Dudgeon DL, et al. Pneumothorax in the Marfan syndrome: prevalence and therapy. Ann Thorac Surg 1984;37:500-4.

59. Wood JR, Bellamy D, Child AH, et al. Pulmonary disease in patients with Marfan syndrome. Thorax 1984;39:780-4.

60. Light RW. Pleural Diseases. Philadelphia, PA: Lippincott Williams \& Wilkins; 2013.

61. Sahn SA, Heffner JE. Spontaneous pneumothorax. N Engl J Med 2000;342:868-74.

62. MacDuff A, Arnold A, Harvey J, et al. Management of spontaneous pneumothorax: British Thoracic Society Pleural Disease Guideline 2010. Thorax 2010;65 Suppl 2:ii18-31.

63. Hatz RA, Kaps MF, Meimarakis G, et al. Long-term results after video-assisted thoracoscopic surgery for firsttime and recurrent spontaneous pneumothorax. Ann Thorac Surg 2000;70:253-7.

64. Inderbitzi RG, Leiser A, Furrer M, et al. Three years' experience in video-assisted thoracic surgery (VATS) for spontaneous pneumothorax. J Thorac Cardiovasc Surg 1994;107:1410-5.

65. König P, Boxer R, Morrison J, et al. Bronchial hyperreactivity in children with Marfan syndrome. Pediatr Pulmonol 1991;11:29-36.

66. Sayeedi I, Widrich J. Methacholine Challenge Test. [Updated 2020 Jun 2]. StatPearls [Internet]. Treasure Island (FL): StatPearls Publishing; 2020.

67. Frischmeyer-Guerrerio PA, Guerrerio AL, Oswald $\mathrm{G}$, et al. TGF receptor mutations impose a strong predisposition for human allergic disease. Sci Transl Med 2013;5:195ra94.

68. Felgentreff K, Siepe M, Kotthoff S, et al. Severe eczema and Hyper-IgE in Loeys-Dietz-syndrome - contribution to new findings of immune dysregulation in connective tissue disorders. Clin Immunol 2014;150:43-50.

69. Carr TF, Zeki AA, Kraft M. Eosinophilic and Noneosinophilic Asthma. Am J Respir Crit Care Med 2018;197:22-37.

70. von Kodolitsch Y, Demolder A, Girdauskas E, et al. Features of Marfan syndrome not listed in the Ghent nosology - the dark side of the disease. Expert Rev Cardiovasc Ther 2019;17:883-915.

71. KATZ HL. Thoracic manifestation in Marfan's syndrome (arachnodactyly). Q Bull Sea View Hosp 1952;13:95-106.

72. Solomon GM, Chan ED. Bronchiectasis. In: Broaddus VC, Ernst JD, King TE, Jr., Lazarus SC, Sarmiento KF, Schnapp LM, Stapleton RD, Gotway MB, editors. Murray and Nadel's Textbook of Respiratory Medicine, Seventh ed. Philadelphis, Pennsylvannia: Elsevier; 2022:941-60.

73. Teoh PC. Bronchiectasis and spontaneous pneumothorax in Marfan's syndrome. Chest 1977;72:672-3.

74. Desai U, Kalamkar S, Joshi JM. Bronchiectasis in a Marfanoid: diagnosis beyond Marfans. Indian J Chest Dis Allied Sci 2014;56:105-7.

75. Foster ME, Foster DR. Bronchiectasis and Marfan's syndrome. Postgrad Med J 1980;56:718-9.

76. Saito H, Iijima K, Dambara T, et al. An autopsy case of Marfan syndrome with bronchiectasis and multiple bullae. Nihon Kyobu Shikkan Gakkai Zasshi 1992;30:1315-21.

77. de Mello KG, Mello FC, Borga L, et al. Clinical and therapeutic features of pulmonary nontuberculous mycobacterial disease, Brazil, 1993-2011. Emerg Infect Dis 2013;19:393-9.

78. Leung JM, Olivier KN, Prevots DR, et al. Beyond Marfan: the clinical impact of bronchiectasis and non-tuberculous mycobacteria in connective tissue diseases. Int J Tuberc Lung Dis 2015;19:1409.

79. Winthrop KL, McNelley E, Kendall B, et al. Pulmonary nontuberculous mycobacterial disease prevalence and clinical features: an emerging public health disease. Am J Respir Crit Care Med 2010;182:977-82.

80. Kartalija M, Ovrutsky AR, Bryan CL, et al. Patients with nontuberculous mycobacterial lung disease exhibit unique body and immune phenotypes. Am J Respir Crit Care Med 2013;187:197-205.

81. Kim RD, Greenberg DE, Ehrmantraut ME, et al. Pulmonary nontuberculous mycobacterial disease: prospective study of a distinct preexisting syndrome. Am J 
Respir Crit Care Med 2008;178:1066-74.

82. Hwang HS, Yi CA, Yoo H, et al. The prevalence of bronchiectasis in patients with Marfan syndrome. Int J Tuberc Lung Dis 2014;18:995-7.

83. Martínez-García MA, de la Rosa Carrillo D, SolerCataluña JJ, et al. Prognostic value of bronchiectasis in patients with moderate-to-severe chronic obstructive pulmonary disease. Am J Respir Crit Care Med 2013;187:823-31.

84. Whitters D, Stockley RA. Bronchiectasis in older patients with chronic obstructive pulmonary disease: prevalence, diagnosis and therapeutic management. Drugs Aging 2013;30:215-25.

85. Lipton RA, Greenwald RA, Seriff NS. Pneumothorax and bilateral honeycombed lung in Marfan syndrome. Report of a case and review of the pulmonary abnormalities in this disorder. Am Rev Respir Dis 1971;104:924-8.

86. Rybczynski M, Koschyk D, Karmeier A, et al. Frequency of sleep apnea in adults with the Marfan syndrome. Am J Cardiol 2010;105:1836-41.

87. Cistulli PA, Sullivan CE. Sleep-disordered breathing in Marfan's syndrome. Am Rev Respir Dis 1993;147:645-8.

88. Young T, Palta M, Dempsey J, et al. Burden of sleep apnea: rationale, design, and major findings of the Wisconsin Sleep Cohort study. WMJ 2009;108:246-9.

89. Peppard PE, Young T, Barnet JH, et al. Increased prevalence of sleep-disordered breathing in adults. Am J Epidemiol 2013;177:1006-14.

90. Muiño-Mosquera L, Bauters F, Dhondt K, et al. Sleep apnea and the impact on cardiovascular risk in patients with Marfan syndrome. Mol Genet Genomic Med 2019; 7:e805.

91. Kohler M, Blair E, Risby P, et al. The prevalence of obstructive sleep apnoea and its association with aortic dilatation in Marfan's syndrome. Thorax 2009;64:162-6.

92. Brooke BS, Habashi JP, Judge DP, et al. Angiotensin II blockade and aortic-root dilation in Marfan's syndrome. N Engl J Med 2008;358:2787-95.

93. Chiu HH, Wu MH, Wang JK, et al. Losartan added to -blockade therapy for aortic root dilation in Marfan syndrome: a randomized, open-label pilot study. Mayo Clin Proc 2013;88:271-6.

94. Groenink M, den Hartog AW, Franken R, et al. Losartan reduces aortic dilatation rate in adults with Marfan syndrome: a randomized controlled trial. Eur Heart J 2013;34:3491-500.

95. Forteza A, Evangelista A, Sánchez V, et al. Efficacy of losartan vs. atenolol for the prevention of aortic dilation in Marfan syndrome: a randomized clinical trial. Eur Heart J 2016;37:978-85.

96. Lacro RV, Dietz HC, Sleeper LA, et al. Atenolol versus losartan in children and young adults with Marfan's syndrome. N Engl J Med 2014;371:2061-71.

97. Nataatmadja M, West J, Prabowo S, et al. Angiotensin II Receptor Antagonism Reduces Transforming Growth Factor Beta and Smad Signaling in Thoracic Aortic Aneurysm. Ochsner J 2013;13:42-8.

98. Sellers SL, Milad N, Chan R, et al. Inhibition of Marfan Syndrome Aortic Root Dilation by Losartan: Role of Angiotensin II Receptor Type 1-Independent Activation of Endothelial Function. Am J Pathol 2018;188:574-85.

99. van Andel MM, Indrakusuma R, Jalalzadeh H, et al. Longterm clinical outcomes of losartan in patients with Marfan syndrome: follow-up of the multicentre randomized controlled COMPARE trial. Eur Heart J 2020;41:4181-7.

100. Hofmann Bowman MA, Eagle KA, Milewicz DM. Update on Clinical Trials of Losartan With and Without $\beta$-Blockers to Block Aneurysm Growth in Patients With Marfan Syndrome: A Review. JAMA Cardiol 2019;4:702-7.

101. Takeda N, Yagi H, Hara H, et al. Pathophysiology and Management of Cardiovascular Manifestations in Marfan and Loeys-Dietz Syndromes. Int Heart J 2016;57:271-7.

102.Habashi JP, Doyle JJ, Holm TM, et al. Angiotensin II type 2 receptor signaling attenuates aortic aneurysm in mice through ERK antagonism. Science 2011;332:361-5.

103. Pereira L, Lee SY, Gayraud B, et al. Pathogenetic sequence for aneurysm revealed in mice underexpressing fibrillin-1. Proc Natl Acad Sci U S A 1999;96:3819-23.

104.Pepe G, Giusti B, Sticchi E, et al. Marfan syndrome: current perspectives. Appl Clin Genet 2016;9:55-65.

105.Lavoie P, Robitaille G, Agharazii M, et al. Neutralization of transforming growth factor-beta attenuates hypertension and prevents renal injury in uremic rats. J Hypertens 2005;23:1895-903.

106. Lee JJ, Galatioto J, Rao S, et al. Losartan Attenuates Degradation of Aorta and Lung Tissue Micromechanics in a Mouse Model of Severe Marfan Syndrome. Ann Biomed Eng 2016;44:2994-3006.

Cite this article as: Tun MH, Borg B, Godfrey M, HadleyMiller N, Chan ED. Respiratory manifestations of Marfan syndrome: a narrative review. J Thorac Dis 2021;13(10):60126025. doi: $10.21037 /$ jtd-21-1064 